Family Profile No. 06, 2018

\title{
Fathers with Resident Minor Children, 2016
}

Author: Kasey J. Eickmeyer

Stepfamilies in the United States are increasingly common (FP-16-09), as a growing share of men are living with children to whom they are not biologically related (stepfathers). Using the 2016 Current Population Survey (CPS), we examine the union status, educational attainment, and average income of three types of fathers with resident minor children: fathers living with only biological children, fathers living with only stepchildren, and fathers living with both stepchildren and biological children.

In 2016, the vast majority (91\%) of fathers who lived with minor children were living with only their biological children. Nearly equal shares ( $4 \%$ and $5 \%$, respectively) of fathers lived with only stepchildren or both stepchildren and biological children. On average, men who were only stepfathers were slightly older (age 42) than fathers with only biological children (41) and fathers with both stepchildren and biological children (38).

Union Status of Fathers with Resident Minor Children

- Most fathers with resident minor children were currently married in 2016 regardless of their biological relationship to resident children.

- It was more common for fathers with only stepchildren to live in cohabiting unions $(13 \%)$ than for fathers with only biological children (7\%) or both step- and biological children (8\%).

Figure 1. Union Status of Fathers with Resident Minor Children by Father Type, 2016

- Married Cohabiting Single

Step- \& Biological

Only Stepfather

$0 \%$
$90 \%$

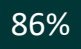

$87 \%$

$50 \%$
$8 \% 2 \%$

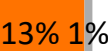

$7 \% 6 \%$

Source: NCFMR analyses of U.S. Census Bureau, Current Population Survey, 2016

\section{...91\% of fathers who lived with minor children were living with only their biological children.}




\section{Educational Attainment of Fathers with Resident Minor Children}

Among fathers with resident minor children, fathers with only biological children had the highest levels of education.

- $64 \%$ of fathers with only biological children had some college education or higher, compared to $52 \%$ of fathers with both step- and biological children and $49 \%$ of fathers with only stepchildren.

- Nearly two-fifths of fathers with only biological children had a bachelor's degree or higher compared to less than a quarter ( $23 \%$ and $19 \%$, respectively) of either fathers with only stepchildren or fathers with both step-and biological children.
Figure 2. Educational Attainment Among Fathers with Minor Children by Father Type, 2016

Less than high school $\quad$ High school

Some college

Bachelor's degree or higher
Step- \& Biological

Only Stepfather

Only Biological Father

$0 \%$

$14 \%$
$35 \%$ $29 \%$ $23 \%$

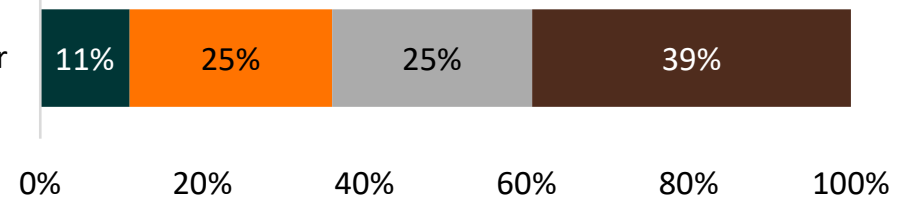

$30 \%$

$19 \%$

Source: NCFMR analyses of U.S. Census Bureau, Current Population Survey, 2016

\section{Average Income of Fathers with Resident Minor Children}

- Fathers with only biological children had the highest average income $(\$ 66,000)$ followed by those with both step- and biological children $(\$ 52,000)$. Fathers with only stepchildren reported an average income of about $\$ 45,000$.
Figure 3. Average Income Among Fathers with Resident Minor Children by Father Type, 2016

$$
\text { Step- \& Biological } \square \text { Only Stepfather } \quad \text { Only Biological Father }
$$

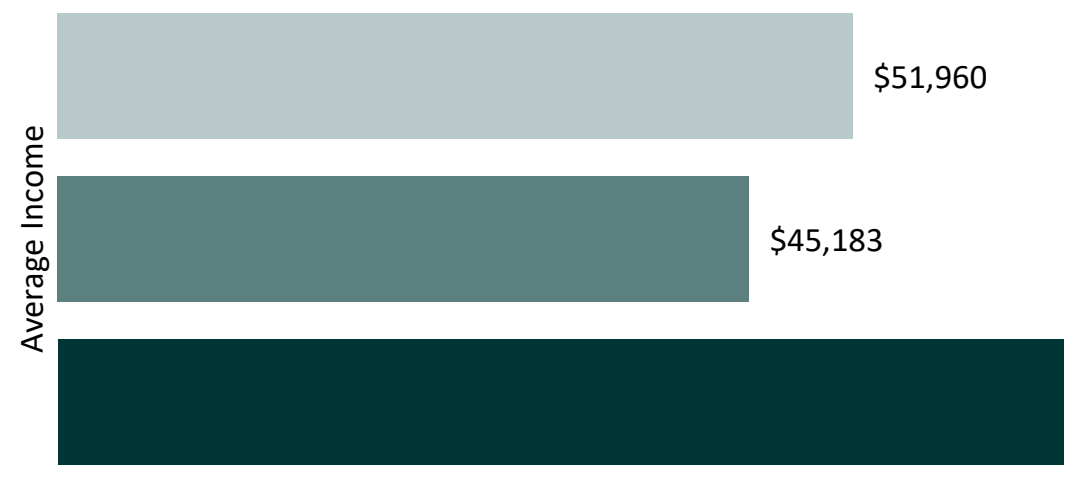

$\$ 65,739$

Source: NCFMR analyses of U.S. Census Bureau, Current Population Survey, 2016

Data Source:

Flood, S., King, M., Ruggles, S., Warren, J.R. (2015). Integrated Public Use Microdata Series, Current Population Survey: Version 4.0. [dataset]. Minneapolis: University of Minnesota. http://doi.org/10.18128/D030.V4.0.

\section{References:}

Guzzo, K.B. (2016). Stepfamilies in the U.S. Family Profiles, FP-16-09. Bowling Green, OH: National Center for Family \& Marriage Research. https://www.bgsu.edu/ncfmr/resources/data/family-profiles/guzzo-stepfamilies-women-fp-16-09.html

\section{Suggested Citation:}

Eickmeyer, K. J. (2018). Fathers with Resident Minor Children, 2016. Family Profiles, FP-18-06. Bowling Green, OH: National Center for Family \& Marriage Research. https://doi.org/10.25035/ncfmr/fp-18-06.

B O O W L I N G G R E E N S T A T E U N I v E R s I T Y
This project is supported with assistance from Bowling Green State University. From 2007 to 2013, support was also provided by the U.S. Department of Health and Human
Services, Office of the Assistant Secretary for Planning and Evaluation. The opinions and conclusions expressed herein are solely those of the author(s) and should not be construed
as representing the opinions or policy of any agency of the state or federal government.

